\title{
Penggunaan Metode QFD Menerjemahkan Suara Konsumen Untuk Pengembangan Lip Product Lavine Beaute
}

\author{
Shelvy Kurniawan ${ }^{1}$, Nabila Dian Nahdi ${ }^{2}$ \\ 1,2 Management Department, BINUS Business School Undergraduate Program, \\ Bina Nusantara University, \\ Jakarta 11480, Indonesia \\ shelvy.kurniawan001@binus.ac.id; \\ nabila.nahdi@binus.ac.id
}

\begin{abstract}
This study aims to bridge the literature gap to examine factors that influence customers in buying a beauty product especially product quality. The type of research used is descriptive. The use of the method in this study is the quality function deployment (QFD) method which has 6 parts namely; customer needs, technical attributes, relationship matrix, technical assessment, correlation matrix, and competitive assessment. The findings of this study are the attributes that meet BPOM standards, ingredients performance, and the probability of failure become one of the attributes that have the highest value on the part of customer needs that can meet customer satisfaction in product development.
\end{abstract}

Keywords - QFD; Quality Function Deployment; Product Quality; Innovation; Product life Cycle.

\begin{abstract}
ABSTRAK
Tujuan Penelitian adalah untuk menjembatani kesenjangan dalam literatur dalam memeriksa faktor yang mempengaruhi konsumen untuk membeli suatu produk kecantikan terutama dalam kualitas produk. Jenis Penelitian yang digunakan adalah deskriptif. Penggunaan metode didalam penelitian ini adalah metode quality function deployment (QFD) yang memiliki 6 bagian yaitu; customer needs, technical attributes, relationship matrix, technical assessment, correlation matrix, dan competitive assessment. Temuan yang dihasilkan penelitian ini adalah bahwa atribut memenuhi standar BPOM, kinerja ingredients, dan probabilitas kegagalan menjadi salah satu atribut yang memiliki nilai tertinggi pada bagian customer needs yang dapat memenuhi kepuasaan pelanggan dalam suatu pengembangan produk.
\end{abstract}

Kata Kunci - QFD; Quality Function Deployment; Kualitas Produk Inovasi; Siklus Hidup Produk.

\section{PENDAHULUAN}

Adanya inovasi produk yang sesuai dengan kebutuhan dan keinginan para wanita Indonesia sebagai konsumen di masa kini ternyata memiliki pengaruh terhadap peningkatan profit suatu perusahaan. Menurut hasil penelitian yang dilakukan oleh Afzali \& Ahmed (2016), Inovasi estetika produk menunjukkan bahwa bagaimana suatu produk harus memiliki perbedaan dari perusahaan lain dan produk pesaing, perbedaan yang dapat dilirik pada pandangan pertama oleh pelanggan adalah warna, bentuk, ukuran dan lain-lain. Perbedaan tersebut dapat dinilai dengan mudah oleh konsumen. Yamamoto \& Lambert (Afzali \& Ahmed, 2016) menjelaskan bahwa peran desain dalam inovasi dapat dipandang sebagai salah satu nilai dan kualitas penawaran suatu perusahaan. Ayodele \& Oluwayeni (2019) dalam studinya juga menyimpulkan bahwa inovasi produk dapat membuat dampak yang signifikan pada kepuasan pelanggan sedangkan kepuasan terjadi ketika harapan dipenuhi atau dilampaui.

Perusahaan perlu melakukan inovasi untuk memenuhi dan melampaui harapan pelanggan. Inovasi produk 
merupakan salah satu cara untuk menjamin kelangsungan hidup suatu produk dan profitabilitas perusahaan.

PT Arya Dharma Putra merupakan salah satu perusahaan lokal yang bergerak dalam mengembangkan produk skin care dan kosmetik. PT Arya Dharma Putra mulai mendirikan dan memasuki Industri Kosmetik pada tahun 2017.

Menurut laporan studi yang dilakukan oleh Nielsen, bahwa konsumen online Indonesia bersedia membayar lebih untuk produk-produk premium yaitu kategori Personal Electronics (komputer, ponsel, tablet, perangkat baca, dll.) sebanyak 63 persen, kategori produk pakaian seperti pakaian/sepatu (41\%), Mobil (37\%), Perhiasan (34\%) dan Kosmetik (32\%) (Nielsen, 2019). Hal ini menunjukkan bahwa masyarakat Indonesia memiliki minat yang cukup tinggi untuk membeli kosmetik sebagai salah satu produk premium yang dapat dibeli melalui online, sehingga kosmetik menjadi peluang yang sangat menggiurkan untuk sebagian besar perusahaan kosmetik di Indonesia yang kian tumbuh.

Sedangkan hasil penelitian yang dilakukan oleh ZAP untuk produk kosmetik menjelaskan bahwa terdapat 5 produk yang memang wajib untuk selalu berada di dalam tas para wanita Indonesia, yaitu (ZAP Beauty Index, 2018):

1. Lipstick $(66,3 \%)$

2. Compact Powder (36,2\%)

3. Lipbalm $(26,4 \%)$

4. Eyebrow Pencil (22,0\%)

5. Oil Control Paper (21,0\%)

Untuk menganalisa mengenai keadaan PT Arya Dharma Putra, peneliti melakukan penganalisaan melalui data profit perusahaan tahun 2018 hingga tahun 2019. Berikut grafik total profit periode Q3- 2018 - Q3-2019 yang diperoleh PT Arya Dharma Putra selama meluncurkan produk, baik skin care maupun kosmetik:

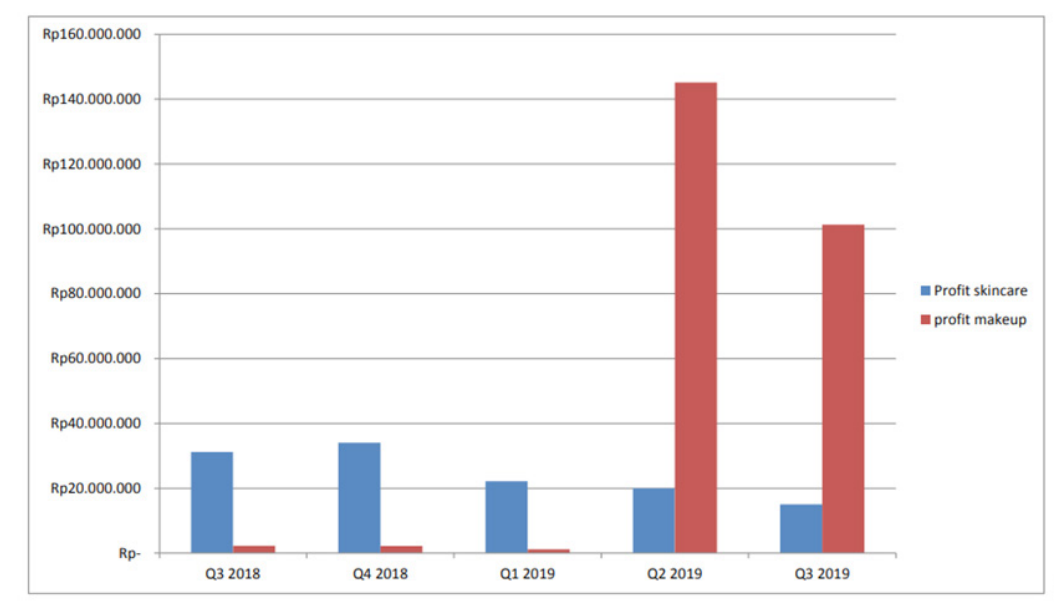

Gambar 1 Total Profit Periode Q3-2018 hingga Q3-2019 PT Arya Dharma Putra.

(Sumber: PT Arya Dharma Putra, 2019)

Berdasarkan gambar 1 terlihat bahwa terjadi adanya penurunan profit yang diperoleh oleh produk kosmetik (Makeup) PT Arya Dharma Putra, terhitung pada periode Q3-2018 hingga Q1-2019 serta Q2-2019 hingga Q32018. Terjadinya penurunan profit disebabkan masa Product Life Cycle yang telah memasuki fase penurunan dikarenakan produk Makeup yang premiere series tidak dapat bersing dengan pesaing. Berdasarkan hasil wawancara, memasuki peluncuran produk kosmetik baru pada Q2-2019, mengalami kenaikan yang mencolok hingga menembus lebih dari 145 juta dibulan pertama peluncuran hingga produk tersebut mengalami penurunan yang tajam pada periode Q3-2019.

Setiap produk memiliki siklus hidup produk. Semakin produk memasuki tahap mature, maka tahap tersebut adalah tahap dimana produk sudah matang dan diterima oleh pasar. Sehingga, perusahaan perlu melakukan invoasi untuk tetap mempertahankan kualitas dan eksistensi dari produk tersebut. Berikut siklus hidup produk untuk kategori La Parfaite Lip Eye Cheek pada PT Arya Dharma Putra: 


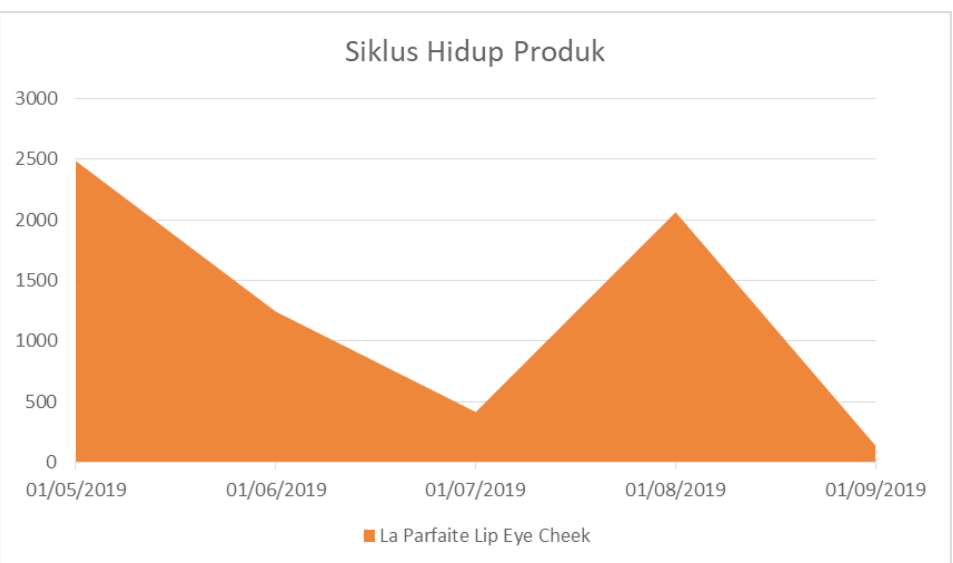

Gambar 2 Siklus Hidup Produk La Parfaite Lip Eye Cheek PT Arya Dharma Putra.

(Sumber: PT Arya Dharma Putera, 2019)

Gambar 2 menunjukkan bahwa La Parfaite Lip Eye Cheek sedang menuju siklus decline. Maka dari itu, PT Arya Dharma Putra melakukan inovasi yang dapat memenuhi kebutuhan konsumen dan memenangkan pasar dari kompetitor dengan produk yang berkualitas.

Dalam penelitian studi yang dilakukan oleh Lee, Goh \& Mohd Noor (2019) menunjukkan bahwa persepsi kualitas memiliki pengaruh positif terhadap niat pembelian. Kualitas merupakan suatu hal yang menggambarkan kepuasaan pelanggan terhadap suatu produk sehingga pelanggan dapat memutuskan untuk melakukan pembelian. Adapun pada Tabel 1 dan Tabel 2 dijelaskan dimensi yang menjadi alat ukur kualitas.

Tabel 1 Dimensi Kualitas Produk

\begin{tabular}{|c|c|c|c|}
\hline \multicolumn{4}{|c|}{ Kualitas Produk } \\
\hline Dimensi & $\begin{array}{l}\text { Zeng, Lee \& } \\
\text { Heung, } 2019\end{array}$ & $\begin{array}{c}\text { Huo, Ye, Zhao \& } \\
\text { Zhu, } 2019\end{array}$ & $\begin{array}{c}\text { Bond et al., } \\
2018\end{array}$ \\
\hline Performance & & $\checkmark$ & $\checkmark$ \\
\hline Realibility & & $\checkmark$ & \\
\hline Durability & & $\checkmark$ & \\
\hline Serviceability & & $\checkmark$ & \\
\hline Aesthetics & & $\checkmark$ & \\
\hline Features & $\checkmark$ & $\checkmark$ & \\
\hline Perceived Quality & $\checkmark$ & $\checkmark$ & $\checkmark$ \\
\hline Conformance to Standard & & $\checkmark$ & $\checkmark$ \\
\hline
\end{tabular}

Sumber: Bond et al. (2018), Huo, Ye, Zhao \& Zhu (2019), dan Zeng, Lee \& Heung (2019).

Tabel 2 Dimensi dan Indikator Kualitas Produk

\begin{tabular}{|c|c|c|c|}
\hline Dimensi & Indikator & Pertanyaan & Kode \\
\hline Performance & Karakteristik Kinerja Produk & $\begin{array}{l}\text { Produk memiliki fokus pada kinerja } \\
\text { Ingredients yang perlu dihindari seperti, } \\
\text { alkohol, paraben, silikon, etc }\end{array}$ & KP1 \\
\hline Realibility & $\begin{array}{l}\text { Probabilitas kegagalan dalam } \\
\text { waktu tertentu }\end{array}$ & $\begin{array}{l}\text { Produk memiliki probabilitas kegagalan } \\
\text { yang minimum seperti meminimalisir tutup } \\
\text { produk tidak gampang retak atau formula } \\
\text { produk tidak luber. }\end{array}$ & KP2 \\
\hline Durability & Masa Hidup & $\begin{array}{l}\text { Produk memiliki masa hidup yang tahan } \\
\text { lama kira kira sekitar } 3 \text { tahun. }\end{array}$ & KP3 \\
\hline \multirow[t]{2}{*}{ Serviceability } & \multirow{2}{*}{$\begin{array}{l}\text { Kepuasan pelanggan } \\
\text { berdasarkan kecepatan, } \\
\text { kesopanan, dan kompetensi } \\
\text { perbaikan, saat dibutuhkan }\end{array}$} & $\begin{array}{l}\text { Frekuensi kecepatan waktu dalam } \\
\text { penukaran jika produk rusak atau cacat. }\end{array}$ & KP4 \\
\hline & & $\begin{array}{l}\text { Menerima layanan customer service yang } \\
\text { responsif dan sopan dalam berkonsultasi } \\
\text { dalam menentukan pembelian produk. }\end{array}$ & KP5 \\
\hline
\end{tabular}




\begin{tabular}{llll}
\hline \multicolumn{1}{c}{ Dimensi } & \multicolumn{1}{c}{ Indikator } & \multicolumn{1}{c}{ Pertanyaan } & Kode \\
\hline Aesthetics & $\begin{array}{l}\text { Bagaimana produk dapat } \\
\text { terlihat dan dirasakan oleh } \\
\text { konsumen }\end{array}$ & Produk memiliki desain visual yang menarik. & KP6 \\
& & & KP7 \\
& Substitutability & $\begin{array}{l}\text { Tampilan produk dapat dirasakan oleh } \\
\text { konsumen sebagai penentuan dalam } \\
\text { pembelian. }\end{array}$ & \\
\hline Features & & $\begin{array}{l}\text { Produk Lip dapat digantikan dengan produk } \\
\text { Lip lain untuk memenuhi kebutuhan sehari - } \\
\text { hari. }\end{array}$ & KP8 \\
\cline { 2 - 4 } & Complementarity & $\begin{array}{l}\text { Produk Lip perlu melibatkan komponen } \\
\text { pelengkap di produk Lip lain agar tampilan }\end{array}$ & KP9 \\
& & terlihat baik. & \\
\hline Perceived Quality & High Quality & $\begin{array}{l}\text { Produk memiliki tingkat kualitas tinggi dari } \\
\text { segi formula dan visual. }\end{array}$ & KP10 \\
\hline Conformance to & Kesesuaian Standarisasi & $\begin{array}{l}\text { Mengutamakan produk yang telah memenuhi } \\
\text { standar BPOM. }\end{array}$ & KP11 \\
\hline Standard & Produk & Sumber: Bond et al. (2018), Huo, Ye, Zhao \& Zhu (2019), dan Zeng, Lee \& Heung (2019). & \\
\hline
\end{tabular}

Quality Function Deployment (QFD) adalah metodologi perencanaan yang sering digunakan untuk menafsirkan Customer Requirement (CR) menjadi Design Requirement (DR). Dalam proses desain produk, sangat penting untuk memperkirakan peringkat prioritas dari persyaratan desain (DR). Bobot kepentingan DR dinilai berdasarkan bobot CR dan intensitas hubungan antara CR dan DR (Li, Tang, Wang \& Zhu, 2019). Quality Function Deployment (QFD) adalah metode yang penting untuk menemukan hubungan antara kebutuhan dan spesifikasi pelanggan. Matriks hubungan yang mewakili hubungan antara kebutuhan setiap pelanggan dan spesifikasi yang telah dibuat dan diikuti oleh perbandingan antara produk terpilih dengan produk pesaing (Fongsatitkul \& Bohez, 2019).

Hasil penelitian yang dilakukan oleh Kapao \& Wattanutchariya (2018) pada bidang kosmetik menunjukkan bahwa Quality Function Deployment (QFD) dilakukan untuk mengevaluasi kebutuhan konsumen dan menemukan persyaratan penting dalam memenuhi standar keselamatan.

Peneliti akan melakukan penelitian agar dapat menentukan kebutuhan dan keinginan konsumen untuk merancang pengembangan produk pada Lip Product di masa depan menggunakan metode QFD.

Berdasarkan data dan teori yang telah dijelaskan mengenai keterkaitan produk inovasi yang memberikan bukti bahwa inovasi memiliki peranan penting pada perusahaan. Maka dari itu, perusahaan perlu lebih adaptif dan responsif terhadap perubahan tren yang dapat membawa inovasi pada produk yang nanti akan diproduksi. Sehingga, peneliti berharap bahwa PT Arya Dharma Putera dapat melakukan inovasi terhadap produknya sehingga dapat mengetahui serta mencapai tren tren yang menjadi kebutuhan konsumen.

\section{METODE PENELITIAN}

Penelitian ini merupakan penelitian deskriptif yang dimana untuk menjelaskan suatu keadaan dari objek tertentu. Unit analisis pada penelitian ini adalah individu, yang subjeknya adalah konsumen PT Arya Dharma Putra (Lavine Beaute). Cakrawala waktu untuk penelitian ini adalah cross-sectional. Peneliti menggunakan data primer dan sekunder. Metode pengumpulan data yang digunakan dalam penelitian ini adalah melalui pencarian literatur dan kuesioner. Sampling desain yang digunakan dalam penelitian ini adalah simple random sampling.

Menurut Sekaran \& Bougie (2016), semakin dekat peneliti ingin hasil sampel mencerminkan karakteristik populasi, maka semakin besar presisi yang harus dituju. Semakin besar presisi yang dibutuhkan, maka semakin besar ukuran sampel yang dibutuhkan, terutama ketika variabilitas dalam populasi itu sendiri besar. Karena keterbatasan waktu dan biaya penelitian, maka peneliti mengambil tingkat presisi $10 \%$ dan tingkat kepercayaan $95 \%$. 
Dalam penelitian ini, peneliti menggunakan metode analisis data yaitu Quality Function Deployment (QFD). Quality Function Deployment (QFD) memiliki 6 bagian, yaitu:

\section{Customer Needs (Whats)}

Bagian ini yang berisi atribut atribut atribut customer needs (Whats). Atribut ini diperoleh dari penelitian pasar yang menggunakan kuesioner. Setelah itu, menghitung Relative Importance Ratings dari masing masing atribut customer needs (Whats) menggunakan rumus:

$$
\begin{aligned}
& \text { Relative importance ratings } \alpha_{m}=\left(\alpha_{m 1}+\alpha_{m 2}+\cdots+\alpha_{m K}\right) / K \\
& =\sum_{K=1}^{K} \alpha_{m k} / K, m=1,2, \ldots, M .
\end{aligned}
$$

Gambar 3 Rumus Relative Importance Rating (Sumber: Wang et. al, 2019)

\section{Technical Attributes (HOWs)}

Bagian ini yang berisi atribut atribut persyaratan teknis (Hows) yang merupakan hasil terjemahan dari customer needs (Whats).

\section{Relationship Matrix}

Bagian ini menggambarkan hubungan hubungan antara customer needs (Whats) dengan persyaratan teknis (Hows) yang setiap hubungan tersebut memiliki simbol dan nilai.

Tabel 3 Simbol dan Nilai di Relationship Matrix.

\begin{tabular}{ccc}
\hline Simbol & Nilai Numerik & Pengertian \\
\hline (Kosong) & 0 & Tidak ada hubungan \\
\hline & 1 & Mungkin ada hubungan \\
\hline & 3 & Hubungannya sedang \\
\hline
\end{tabular}

\section{Technical Assessment}

Bagian QFD yang bertujuan untuk mengetahui urutan tingkat kepentingan (ranking) persyaratan teknis (Technical attributes) yang disesuaikan dengan kebutuhan konsumen.

Perhitungan Technical Assessment yaitu melalui nilai bobot kolom atau absolute weight. Untuk mengetahui nilai bobot kolom, menurut Wijaya (2017), absolute weight merupakan penjumlahan dari perkalian antara Importance Rating dengan masing masing tingkat hubungan antara Customer Needs (Whats) dengan Technical attributes (Hows).

\section{Correlation Matrix}

Correlation Matrix bertujuan untuk menunjukkan hubungan antar suatu persyaratan teknis dengan persyaratan teknis lainnya. Tingkat hubungan kekuatan antar matriks ditentukan dengan simbol tertentu dan nilai tertentu, baik positif, negatif ataupun tanpa korelasi.

\section{Competitive Assessment}

Untuk menghitung Competitive Assessment, dibutuhkan data perbandingan mengenai kebutuhan konsumen dengan produk pesaing. Maka dari itu, untuk mendapatkan data pesaing maka dibutuhkan kuesioner yang berisi atribut atribut pertanyaan mengenai kepuasaan konsumen menggunakan produk pesaing. Competitive Assessment dinilai dengan menggunakan Relative Importance Ratings, Goal, dan Improvement Rasio. 
Penentuan Goal secara normal ditentukan bersama dengan pihak PT Arya Dharma Putera menggunakan skala kuantitatif yang sama sebagai suatu tingkat pencapaian.

Untuk menghitung Improvement Ratio menggunakan rumus dibawah ini:

$$
\text { Improvement ratio } \gamma_{m}=g_{m} / x_{m 1}
$$

Gambar 4 Rumus Improvement Ratio

(Sumber: Wang et. al, 2019)

Keterangan:

$\mathrm{g}_{\mathrm{m}}=$ Sasaran untuk masing masing customer needs (Whats)

$\mathrm{X}_{\mathrm{m}}=$ Relative Importance Ratings atau customer satisfaction performance

\section{HASIL DAN PEMBAHASAN}

\section{Customer Needs (Whats)}

Range nilai nilai yang telah dihitung berdasarkan customer needs (Whats) bertujuan untuk mengetahui seberapa penting kebutuhan konsumen terhadap kualitas suatu produk tersebut. Berikut ini adalah tabel nilai Relative Importance Rating dan Ranking yang berisikan nilai kepentingan konsumen (Importance Rating):

Tabel 4 Nilai Importance Rating Customer Needs (Whats)

\begin{tabular}{lll}
\hline \multicolumn{1}{c}{ Customer Needs (Whats) } & $\begin{array}{c}\text { Relative Importance } \\
\text { Rating }\end{array}$ & Rank \\
\hline Kinerja Ingredients (KP1) & 8,05 & 2 \\
\hline Probabilitas Kegagalan (KP2) & 8,03 & 3 \\
\hline Masa Hidup (KP3) & 6,88 & 10 \\
\hline Frekuensi kecepatan waktu penukaran (KP4) & 7,31 & 6 \\
\hline Layanan Customer Service (KP5) & 7,80 & 4 \\
\hline Desain Visual (KP6) & 7,29 & 7 \\
\hline Tampilan Produk (KP7) & 7,12 & 8 \\
\hline Produk Lip dapat digantikan (KP8) & 7,04 & 9 \\
\hline Komponen pelengkap (KP9) & 6,42 & 11 \\
\hline Kualitas tinggi (KP10) & 7,64 & 5 \\
\hline Memenuhi Standar BPOM (KP11) & 8,40 & 1 \\
\hline Sumber: Peneliti (2020) & & 6 \\
\hline
\end{tabular}

Sumber: Peneliti (2020)

\section{Technical Attributes (HOWs)}

Persyaratan teknis merupakan bahasa teknis yang muncul dari terjemahan kebutuhan konsumen (Customer Need) dengan tujuan agar harapan konsumen dapat terpenuhi. Pada penelitian in persyaratan teknis didapatkan dari hasil diskusi direktur PT Arya Dharma Putera (Lavine Beaute). Data atribut persyaratan teknis merupakan hasil murni yang diberikan oleh narasumber dalam merancang satu produk. Berikut merupakan persyaratan teknis yang telah dirangkum:

Tabel 5 Technical Attributes (Hows)

\begin{tabular}{cl}
\hline No & \multicolumn{1}{c}{ HOWs } \\
\hline 1 & Formula \\
\hline 2 & Dimensi Produk Lip \\
\hline 3 & Berat Produk Lip \\
\hline 4 & Masa Hidup \\
\hline 5 & Penyediaan Layanan Konsultasi \\
\hline 6 & Konsistensi Pengiriman \\
\hline
\end{tabular}




\begin{tabular}{cl}
\hline No & \multicolumn{1}{c}{ HOWs } \\
\hline 7 & Warna Kemasan \\
\hline 8 & Desain Kemasan \\
\hline 9 & Jumlah Warna \\
\hline 10 & Kesolidan Bahan \\
\hline 11 & Daya tahan terhadap lingkungan \\
\hline Sumber:PT Arya Dharma Putera (2020)
\end{tabular}

House Of Quality (HOQ) merupakan voice of customer yang perlu diperhatikan dan didengar oleh PT Arya Dharma Putera karena voice of customer merupakan salah satu proses masuk ke dalam suatu desain, proses dan produksi bahkan hingga ke pelayanan yang ditawarkan oleh perusahaan. House Of Quality (HOQ) memiliki bagian bagian yang berfungsi sebagai salah satu dasar pengembangan produk yaitu; customer needs (Whats), Importance Rating, Technical attributes (Hows), Correlation Matrix, Relationship Matrix, Technical Assessment, dan Competitive Assessment.

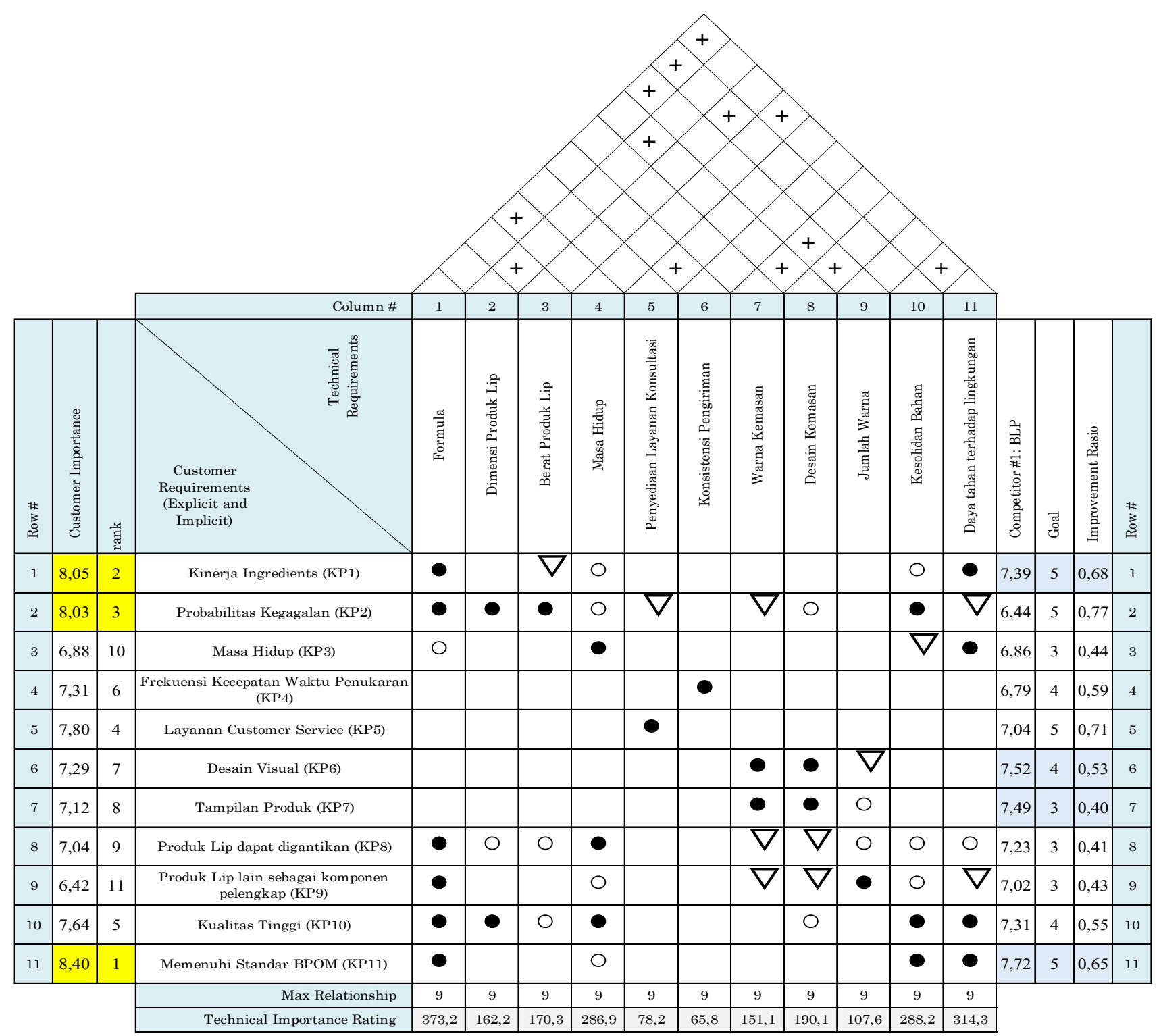

Gambar 5 House Of Quality (HOQ)

(Sumber: Peneliti, 2020)

Bagian pertama yaitu customer needs (Whats) Terdapat 3 (tiga) atribut yang memiliki nilai Relative Importance Ratings diangka 8 (delapan) atau tertinggi dibandingkan atribut lain yang dapat menjadi fokus perusahaan dalam mengembangkan produknya adalah KP11 (memenuhi standar BPOM), KP1 (kinerja ingredients), dan KP2 (probabilitas kegagalan). 
Perhitungan bagian Technical Assessment yaitu melalui nilai bobot kolom atau absolute weight berdasarkan hubungan antara customer needs (Whats) dengan Technical attributes (Hows). Nilai absolute weight pada bagian Technical Assessment tertinggi yaitu atribut formula dengan nilai 373,2 daya tahan terhadap lingkungan dengan nilai 314,3, kesolidan bahan dengan nilai 288,2 dan masa hidup dengan nilai 286,9.

Bagian Correlation Matrix menggunakan simbol dalam melakukan analisa untuk mengetahui keterkaitan persyaratan teknis satu dengan persyaratan teknis lainnya. Persyaratan teknis yang sangat banyak mempengaruhi persyaratan teknis lainnya adalah formula.

Berikut nilai kuesioner yang telah dikumpulkan oleh peneliti untuk masing masing indikator yang terdapat ditabel.

Tabel 6 Nilai Kuesioner

\begin{tabular}{clllc}
\hline Dimensi & \multicolumn{1}{c}{ Indikator } & \multicolumn{1}{c}{ Pertanyaan } & Kode & Nilai \\
\hline Performance & Karakteristik Kinerja & $\begin{array}{l}\text { Produk memiliki fokus pada kinerja } \\
\text { Ingredients yang perlu dihindari } \\
\text { seperti, alkohol, paraben, silikon, etc }\end{array}$ & & 0,564 \\
& & KP1 & \\
\hline
\end{tabular}

\begin{tabular}{llll}
\hline Realibility & $\begin{array}{l}\text { Probabilitas kegagalan } \\
\text { dalam waktu tertentu }\end{array}$ & $\begin{array}{l}\text { Produk memiliki probabilitas } \\
\text { kegagalan yang minimum seperti }\end{array}$ & \\
& $\begin{array}{ll}\text { meminimalisir tutup produk tidak } \\
\text { gampang retak atau formula produk }\end{array}$ & \\
& tidak luber.
\end{tabular}

\begin{tabular}{|c|c|c|c|c|}
\hline Durability & Masa Hidup & $\begin{array}{l}\text { Produk memiliki masa hidup yang } \\
\text { tahan lama kira kira sekitar } 3 \text { tahun. }\end{array}$ & KP3 & 0,555 \\
\hline \multirow[t]{2}{*}{ Serviceability } & \multirow{2}{*}{$\begin{array}{l}\text { Kepuasan pelanggan } \\
\text { berdasarkan kecepatan, } \\
\text { kesopanan, dan } \\
\text { kompetensi perbaikan, } \\
\text { saat dibutuhkan }\end{array}$} & $\begin{array}{l}\text { Frekuensi kecepatan waktu dalam } \\
\text { penukaran jika produk rusak atau } \\
\text { cacat. }\end{array}$ & KP4 & 0,674 \\
\hline & & $\begin{array}{l}\text { Menerima layanan customer service } \\
\text { yang responsif dan sopan dalam } \\
\text { berkonsultasi dalam menentukan } \\
\text { pembelian produk. }\end{array}$ & KP5 & 0,691 \\
\hline \multirow[t]{2}{*}{ Aesthetics } & \multirow{2}{*}{$\begin{array}{l}\text { Bagaimana produk } \\
\text { dapat terlihat dan } \\
\text { dirasakan oleh } \\
\text { konsumen }\end{array}$} & $\begin{array}{l}\text { Produk memiliki desain visual yang } \\
\text { menarik. }\end{array}$ & KP6 & 0,731 \\
\hline & & $\begin{array}{l}\text { Tampilan produk dapat dirasakan } \\
\text { oleh konsumen sebagai penentuan } \\
\text { dalam pembelian. }\end{array}$ & KP7 & 0,687 \\
\hline \multirow[t]{2}{*}{ Features } & Substitutability & $\begin{array}{l}\text { Produk Lip dapat digantikan } \\
\text { dengan produk Lip lain untuk } \\
\text { memenuhi kebutuhan sehari - hari. }\end{array}$ & KP8 & 0,708 \\
\hline & Complementarity & $\begin{array}{l}\text { Produk Lip perlu melibatkan } \\
\text { komponen pelengkap di produk Lip } \\
\text { lain agar tampilan terlihat baik. }\end{array}$ & KP9 & 0,682 \\
\hline Perceived Quality & High Quality & $\begin{array}{l}\text { Produk memiliki tingkat kualitas } \\
\text { tinggi dari segi formula dan visual. }\end{array}$ & KP10 & 0,641 \\
\hline $\begin{array}{l}\text { Conformance to } \\
\text { Standard }\end{array}$ & $\begin{array}{l}\text { Kesesuaian } \\
\text { Standarisasi Produk }\end{array}$ & $\begin{array}{l}\text { Mengutamakan produk yang telah } \\
\text { memenuhi standar BPOM. }\end{array}$ & KP11 & 0,598 \\
\hline
\end{tabular}

Sumber: Peneliti (2020)

Menurut pengamatan peneliti, bahwa terdapat kesenjangan antara kebutuhan konsumen antara di lapangan dengan persepsi perusahaan, maka dari itu, merangkum dari hasil kuesioner, PT Arya Dharma Putera perlu memerhatikan hal hal berikut yang berkaitan dengan customer needs (Whats): 
- Berdasarkan standar BPOM untuk produk kosmetik adalah:

Bahan bahan yang dilarang karena tidak sesuai dengan standar BPOM adalah bahan pengawat, bahan pewarna, dan bahan tabir surya yang tidak tercantum PE KBPOM No. HK.00.05.42.1018

- Kinerja Ingredients yang sesuai dengan kebutuhan konsumen adalah:

1. Formula Ringan

2. Enviromentally friendly

3. Paraben free, alcohol free dan silikon free

- Probabilitas kegagalan:

1. Tutup botol tidak pecah

2. Isi lip product tidak berubah warna sebelum tenggat masa hidup

3. Isi lip product tidak gampang tumpah

PT Arya Dharma Putra (Lavine Beaute) perlu memiliki fokus yang lebih pada 4 (empat) atribut persyaratan teknis atau Technical attributes (Hows) tersebut. Hal itu dikarenakan atribut persyaratan teknis yang memiliki nilai absolute weight sudah dapat memenuhi dengan kebutuhan konsumen.

- Untuk atribut formula berfokus pada formula yang tidak menyebabkan berat saat pengaplikasian ke bibir, formula yang dapat digunakan adalah penggunaan formula vit $\mathrm{A}$, Vit $\mathrm{C}$, dan antioxidants, sehingga menyebabkan formula lebh ringan dan melembabkan bibir.

- Untuk daya tahan terhadap lingkungan, PT Arya Dharma Putera (Lavine Beaute) perlu menghindari produk yang mengandung paraben, dyes dan guilt. Serta untuk packaging terhadap lip product perlu menggunakan package yang bisa didaur ulang atau digunakan kembali.

- Untuk kesolidan bahan, penentuan formula perlu diperhatikan karena mempengaruhi kesolidan bahan yang akhirnya memiliki pengaruh pada masa hidup produk tersebut.

\section{KESIMPULAN}

Customer needs (Whats) merupakan atribut paling penting untuk memenuhi kebutuhan konsumen dalam suatu produk. Customer needs (Whats) menjadi landasan utama dalam menerjemahkan menjadi persyaratan teknis untuk membuat suatu produk sesuai standar yang telah ditetapkan oleh perusahaan. Maka dari itu, tingkatan Importance pada atribut - atribut pada Lip Product yang sesuai dengan kebutuhan konsumen berdasarkan pada 8 dimensi kualitas produk yang diadopsi dari penelitian sebelumnya.

Hasil dari tingkat importance tertinggi hingga terendah dari atribut kebutuhan konsumen yaitu; memenuhi standar BPOM (KP11), kinerja ingredients (KP1), probabilitas kegagalan (KP2), layanan customer service (KP5), tingkat kualitas tinggi (KP10), frekuensi kecepatan waktu penukaran (KP4), desain visual (KP6), tampilan produk (K7), produk lip dapat digantikan (KP8), masa hidup (KP3) dan komponen pelengkap (KP9). Nilai Relative Importance Ratings yang memiliki dominan untuk diterapkan untuk memenuhi kebutuhan konsumen adalah memenuhi standar BPOM (KP11) dengan nilai 8,40 lalu diikuti kinerja ingredients (KP1) dengan nilai 8,05, serta probabilitas kegagalan (KP2) dengan nilai 8,03.

Sebaiknya perusahaan memenuhi kebutuhan konsumen dan menjadikan kebutuhan konsumen tersebut sebagai landasan atribut yang dapat diterjemahkan ke persyaratan teknis yang lebih kompleks lagi seperti tinggi lip product, desain cincin antara tutup dengan badan kemasan, lapisan kemasan lip product, diameter lip product, dll. Selain itu, perusahaan perlu mengembangkan produk dan meningkatkan kualitas produk sesuai dengan perhitungan metode Quality Function Deployment (QFD) agar dapat menghemat elemen elemen yang tidak diinginkan selama proses perancangan produk serta dapat memenuhi kebutuhan konsumen. Penggunaan metode Quality Function Deployment (QFD) secara berkala dapat mengurangi ketidakpuasaan konsumen terhadap suatu produk sehingga dapat meningkatkan dan mempertahankan eksistensi produk tersebut.

Memperhatikan persyaratan teknis juga perlu karena atribut atribut tersebut dapat mempengaruhi persyaratan teknis satu dengan yang lainnya. Yang perlu sangat diperhatikan oleh perusahaan adalah formula. Formula mempengaruhi banyak persyaratan teknis lainnya yaitu, masa hidup, kesolidan bahan, daya tahan terhadap lingkungan serta warna. Sehingga atribut persyaratan teknis tersebut perlu diperhatikan dengan baik agar dapat mengurangi kegagalan pada suatu produk. 


\section{DAFTAR PUSTAKA}

Afzali, M., \& Ahmed, E. (2016). Exploring consumer doubt towards local new products innovation and purchase intention. World Journal Of Entrepreneurship, Management And Sustainable Development, 12(1), 2-17. doi: 10.1108/wjemsd-05-2015-0022

Ayodele, M., \& Oluwayeni, O (2019). Effecr of product innovation on customer satisfaction: An overview of insight into Nigerian servicemarket. Noble International Journal of Social Sciences Research, 04(01), $1-7$.

Bond, A., Retief, F., Cave, B., Fundingsland, M., Duinker, P., Verheem, R., \& Brown, A. (2018). A contribution to the conceptualisation of quality in impact assessment. Environmental Impact Assessment Review, 68, 49-58. doi: 10.1016/j.eiar.2017.10.006

Fongsatitkul, T., \& Bohez, E. (2019). Application of A QECN-QFD to Design An Enviromentally-Friendly One Handed Lipstick Packaging. Engineering Journal of Research and Development, 121 - 134.

Huo, B., Ye, Y., Zhao, X., \& Zhu, K. (2019). Supply chain quality integration: A taxonomy perspective. International Journal Of Production Economics, 207, 236-246. doi: 10.1016/j.ijpe.2016.05.004

Kapao, N., \& Wattanutchariya, W. (2018). Development of natural acne patch from local materials using Quality Function Deployment technique. MATEC Web Of Conferences, 192, 01050. doi: 10.1051/matecco$\mathrm{nf} / 201819201050$

Lee, J., Goh, M., \& Mohd Noor, M. (2019). Understanding purchase intention of university students towards skin care products. PSU Research Review, 3(3), 161-178. doi: 10.1108/prr-11-2018-0031

Li, S., Tang, D., Wang, Q., \& Zhu, H. (2019). Analysis and Extraction of Consumer Information for the Evaluation of Design Requirement Depending on Consumer Involvement. Advances In Mechanical Design, 342353. doi: 10.1007/978-981-32-9941-2_29

Nielsen. (2019). Online Sales of Premium Products Surging Around the World. Diperoleh dari: https://www.nielsen.com/mau/en/insights/article/2019/online-sales-of-premium-products-surging-around-the-world-article-april-2019/

Sekaran, U., \& Bougie, R. (2016). Research Methods for Business: A Skill-Building Approach Seventh Edition.

Wang, L., Jin, J., \& Zhou, K. (2019). Institutional forces and customer participation in new product development: A Yin-Yang perspective. Industrial Marketing Management, 82, 188-198. Doi: 10.1016/j.indmarman.2019.01.015s

Wijaya, T. (2017). Manajemen Kualitas Jasa: Desain Servqual, QFD dan Kano. Edisi-2. Indeks, Jakarta.

Zeng, F., Lee, S., \& Heung, C. (2019). Consumer attitudes toward downward extensions: an exploration of Giordano's extension in Hong Kong. Fashion And Textiles, 6(1). doi: 10.1186/s40691-019-0185-1

ZAP. (2019). ZAP Beauty Index. Diperoleh dari: https://zapclinic.com/zapbeautyindex 